\title{
Características fotossintéticas de batata cv. Baronesa e seu genótipo transformado geneticamente para resistência ao PVY
}

\author{
Marcos Antonio Bacarin ${ }^{1,3}$; Douglas Damé Schmitz ${ }^{1,4}$; Antelmo Ralph Falqueto ${ }^{1,4}$; Daniela Cassol ${ }^{1,5}$; \\ Antonio Carlos Torres ${ }^{2}$; José Antonio Peters ${ }^{1}$; Eugenia Jacira Bolacel Braga ${ }^{1}$ \\ ${ }^{1}$ UFPel-Dep ${ }^{\text {to }}$ Botânica, C. Postal 354, 96010-906 Pelotas-RS; ${ }^{2}$ Embrapa Hortaliças, C. Postal 218, 70359-970 Brasília-DF; ${ }^{3}$ Pesquisador \\ CNPq (autor de correspondência); ${ }^{4}$ Bolsista CAPES; ${ }^{5}$ Bolsista PIBIC/UFPel/CNPq; bacarin @ ufpel.edu.br.
}

\section{RESUMO}

O melhoramento genético da batata é complexo e requer uma grande demanda de tempo e energia. A tecnologia do DNA recombinante, com sua capacidade potencial de isolar e transferir genes a partir de qualquer organismo, permite incorporar nas plantas novos caracteres de interesse agrícola. No entanto, as conseqüências da inserção de determinados genes em relação às características fisiológicas da planta são, muitas vezes desconhecidas. O presente trabalho teve como objetivo avaliar as características fotossintéticas de plantas de batata cultivar Baronesa modificadas geneticamente com genes de resistência a vírus. Para isso, tubérculos de batata cultivar Baronesa e seu respectivo genótipo transformado foram plantados em vasos e mantidos em casa de vegetação. Durante o ciclo de vida das plantas foram avaliados parâmetros da fluorescência das clorofilas, fotossíntese líquida e fotossíntese potencial. As plantas de batata cv. Baronesa transformadas com genes de resistência ao vírus PVY apresentaram maior eficiência fotoquímica máxima e maior taxa de liberação de oxigênio do que plantas da mesma cultivar não modificadas geneticamente, embora tivessem mantido os demais parâmetros de fluorescência das clorofilas e a taxa de fotossíntese líquida iguais.

Palavras-chave: Solanum tuberosum, fluorescência das clorofilas, transformação genética.

\section{ABSTRACT}

Photosynthetic characteristics of potato plants, cv. Baronesa and its genetically transformed genotype for PVY resistance

Potato breeding is difficult and requires a great deal of time and energy. The use of recombinant DNA technology, with its potential capacity of isolating and transferring genes from any organism, allows incorporating in plants new characters of agricultural interest. However, consequences of the incorporation of determined genes on physiological characteristics are sometimes unknown. In this study we evaluated photosynthetic characteristics of potato plants genetically modified with resistance genes to PVY. Potato tubers of $\mathrm{cv}$. Baronesa and its respective transformed genotype were planted in pots and kept in greenhouse. During the plant life cycle, parameters of chlorophyll fluorescence, net photosynthesis and potential photosynthesis were evaluated. Plants transformed with PVY resistant genes showed higher maximum photochemical efficiency and higher oxygen evolution rate, however the parameters of chlorophyll fluorescence and net photosynthesis were the same.

Keywords: Solanum tuberosum, chlorophyll fluorescence, genetic transformation.

(Recebido para publicação em 8 de maio de 2007; aceito em 3 de junho de 2008)

$\mathrm{O}$ Rio Grande do Sul apresenta uma das maiores áreas plantadas com batata no país; no entanto, a produtividade média é muito baixa, devido, principalmente, à falta de adoção de tecnologias, como por exemplo o plantio de batata-semente certificada. A cultivar Baronesa foi desenvolvida na Embrapa Clima Temperado (Pereira $e t$ al., 2003), sendo caracterizada por plantas de porte baixo a médio e semi-ereto, com quatro a cinco hastes. Seu ciclo é médio e possuem tubérculos com formato alongado e achatado, olhos rasos e salientes, película rosa e lisa, e polpa creme (Pereira et al., 2003).

Esta cultivar é altamente suscetível a doenças, principalmente viroses causadas pelo Potato virus X (PVX), Potato virus $Y$ (PVY) e pelo Potato leafroll virus (PLRV) (Costa et al., 1989;
Ferreira et al., 1999). As plantas afetadas pelo vírus PVY mostram fortes alterações morfológicas e fisiológicas, associadas com mudanças na estrutura e função dos cloroplastos (Zhou et al., 2004). O ataque pelo PVY resulta na diminuição na fotossíntese, principalmente pela interferência com os processos enzimáticos no ciclo de Calvin, que resultam em uma regulação no transporte de elétrons. Segundo Zhou et al. (2004), plantas de batata da cultivar Chunzao infectadas pelo PVY apresentaram uma produção de tubérculos $20 \%$ menor quando comparada com plantascontrole.

A batata é considerada uma planta ideal para transformação genética (Foxe, 1992) devido às dificuldades com seu melhoramento (Truskinov \& Rogozina, 1997) e à facilidade de ser geneticamen- te transformada e regenerada in vitro, bem como a propagação que permite uma expansão clonal dos transformantes (Vayda \& Belknap, 1992).

A tecnologia do DNA recombinante, com sua capacidade potencial de isolar e transferir genes, permite incorporar nas plantas novos caracteres de interesse agrícola (Borém, 2001). Desta forma, enquanto incorpora um caráter novo, a variedade transgênica mantém intacta sua base genética e seu potencial produtivo original, permitindo abreviar o melhoramento de cultivares já utilizadas comercialmente.

Entretanto, as consequiências da inserção de determinados genes (DNA exógeno) com relação às características fisiológicas da planta, como as fotossintéticas, na maioria das vezes são desconhecidas, sendo necessários estu- 
dos para a verificação de possíveis alterações metabólicas em decorrência da transgênia. Outro problema encontrado nos experimentos que envolvem a transformação genética de plantas é a instabilidade da expressão do gene inserido "transgene" (Slater et al., 2003). Alguns genes introduzidos não são expressos como deveriam (Grant, 1999), e fenômenos como co-supressão, epistasia e silenciamento gênico podem ser freqüentemente observados (Brasileiro \& Dusi, 1999).

O uso de parâmetros de fluorescência tem permitido o estudo de características relacionadas à capacidade de absorção e transferência da energia luminosa na cadeia de transporte de elétrons, sendo possíveis também estudos das mudanças conformacionais dos tilacóides (Krause \& Weis, 1991; Maxwell \& Johnson, 2000; Rohácek, 2002). A relação inversa entre a fluorescência das clorofilas in vivo e a atividade fotossintética pode ser usada para detectar efeitos na atividade fotossintética potencial de folhas e de estresses sobre plantas (Allahverdiev et $a l .$, 1998). Além disso, a avaliação durante o ciclo de vida das plantas possibilita informações mais precisas, tais como variações nos parâmetros de fluorescência, com as mudanças nos estádios de desenvolvimento das plantas (Bacarin \& Mosquin, 2002).

O presente trabalho teve como objetivo avaliar as características fotossintéticas de batata cultivar Baronesa, comparado com seu genótipo transformado geneticamente com genes de resistência ao vírus Y.

\section{MATERIAL E MÉTODOS}

Foram utilizados tubérculos de batata (Solanum tuberosum L.) da cultivar Baronesa e de plantas geneticamente transformadas, via sistema Agrobacterium, da mesma cultivar. A presença do plasmídeo pBI-PVY, que contém o gene $\mathrm{CP}$ que codifica para a proteína do capsídeo do vírus $\mathrm{Y}$ e que confere resistência ao PVY, foi confirmada, nestas plantas, através de técnicas de PCR, bioensaios e "Southern blot" (Campos, 1995; Ferreira et al., 1999). Cada tubérculo foi plantado in- dividualmente em um vaso plástico, com capacidade para oito litros, contendo mistura de solo planossolo previamente peneirado e areia, na proporção de 5:1. As plantas foram mantidas em casa de vegetação com umidade relativa entre $75-80 \%$ e temperatura entre 23 $28^{\circ}$.C, até o final do experimento (116 dias).

Os parâmetros da cinética de indução da fluorescência das clorofilas foram determinados, para cada genótipo, aos 51, 65, 79, 93 e 107 dias após o plantio (DAP), conforme modelo descrito por Rohácek (2002) usando fluorômetro modulado (FMS-2, Hansatech, King's Lynn, UK). Folhas do segundo nó a partir da gema apical foram adaptadas ao escuro (estado adaptado ao escuro, EAE) por 15 min e depois irradiadas por feixe de baixa modulação $\left(0,12 \mu \mathrm{mol} \mathrm{m} \mathrm{m}^{-2} \mathrm{~s}^{-1}\right)$ para determinação dos parâmetros da fluorescência inicial $\left(\mathrm{F}_{0}\right)$ e a fluorescência máxima $\left(\mathrm{F}_{\mathrm{M}}\right)$ foi determinada após o pulso de saturação do fóton $\left(4.000 \mu \mathrm{mol} \mathrm{m} \mathrm{m}^{-2} \mathrm{~s}^{-1}\right)$. A relação $F_{v} / F_{M}$ (eficiência fotoquímica máxima) foi calculada a partir dos parâmetros $\mathrm{F}_{0}$ e $\mathrm{F}_{\mathrm{M}}$, sendo $\mathrm{F}_{\mathrm{V}}$ (fluorescência variável $)=\left(\mathrm{F}_{\mathrm{M}}-\mathrm{F}_{0}\right)$.

Determinados os parâmetros no EAE, as folhas foram submetidas à luz actínica por 5 min para a determinação dos parâmetros do estado adaptado à luz (EAL): fluorescência máxima na luz $\left(\mathrm{F}_{\mathrm{M}}{ }^{\prime}\right)$ e fluorescência inicial na luz $\left(\mathrm{F}_{0}{ }^{\prime}\right)$. A partir destes foram obtidos os seguintes parâmetros: fluorescência variável no EAL $\left(\mathrm{F}_{\mathrm{v}}{ }^{\prime}=\mathrm{F}_{\mathrm{M}}{ }^{\prime}-\mathrm{F}_{0}{ }^{\prime}\right)$; coeficiente de extinção fotoquímico $(\mathrm{qP})$, coeficiente de extinção não-fotoquímico (qN) e $\Phi_{2}$ (eficiência atual ou produção quântica fotoquímica efetiva do FS II $-\mathrm{F}_{\mathrm{V}}$ ' $/ \mathrm{F}_{\mathrm{M}}$ ') (Rohácek, 2002). Os valores dos parâmetros de fluorescência foram normalizados em relação à $\mathrm{F}_{0}$ de acordo Rohácek \& Barták (1999).

Aos 51, 65, 79, 93 e 107 dias após o plantio e nas mesmas folhas utilizadas nas determinações de fluorescência, foi realizada a medição da taxa de fotossíntese líquida, utilizando-se um analisador de gases a infravermelho, sistema aberto ( $\mathrm{LCi}, \mathrm{ADC}, \mathrm{UK})$, sendo a taxa expressa em $\mu$ mol $\mathrm{CO}_{2} \mathrm{~m}^{-2} \mathrm{~s}^{-1}$.

A taxa de liberação de oxigênio (fotossíntese potencial), expressa em $\mu \mathrm{mol} \mathrm{O}_{2} \mathrm{~m}^{-2} \mathrm{~s}^{-1}$, foi estimada pela taxa de liberação de oxigênio sendo realizada aos 54, 68, 83, 98 e 110 DAP, utilizando-se a mesma folha em que foram medidos os parâmetros de fluorescência e fotossíntese líquida. Para tanto, foi utilizado um eletrodo de oxigênio de fase gasosa (Leaflab 2, Hansatech, King's Lynn, UK), com aproximadamente $5 \%$ de $\mathrm{CO}_{2}$ no interior da câmara, fornecido por tampão carbonato e fluxo de fótons de radiação fotossinteticamente ativa de $2000 \mu \mathrm{mol}$ $\mathrm{m}^{-2} \mathrm{~s}^{-1}$, medido por meio sensor quântico QSRED (Hansatech, King ‘s Lynn, UK).

O delineamento experimental, para as características fotossintéticas, foi inteiramente casualizado, em esquema fatorial $2 \times 5$, sendo dois genótipos e cinco épocas de análise, correspondendo a dias após o plantio (DAP). Os dados foram submetidos à análise de variância e as médias dos tratamentos foram comparadas pelo teste de Tukey ao nível de significância de 5\%. Para cada genótipo foram utilizados cinco vasos, contendo uma planta em cada, totalizando cinco repetições por tratamento.

\section{RESULTADOS E DISCUSSÃO}

A análise da eficiência fotoquímica máxima (relação $\mathrm{F}_{\mathrm{V}} / \mathrm{F}_{\mathrm{M}}$ ) não apresentou interação significativa entre os fatores genótipo e época de análise, sendo apenas significativos os fatores isolados. A relação $\mathrm{F}_{\mathrm{V}} / \mathrm{F}_{\mathrm{M}}$ foi menor no genótipo não-transformado $(0,816)$ em comparação com o transformado $(0,835)$. Entretanto, quanto ao fator data de análise, não foi observada diferença significativa até os 93 dias após o plantio, havendo um decréscimo apenas aos 107 dias (Tabela 1). Tal fato pode ser resultado da senescência das plantas, que neste período já se encontravam em fase final do ciclo de crescimento. Apesar de nãosignificativa a interação entre genótipo e época de análise, observou-se que para as plantas não-transformadas a queda na relação $\mathrm{F}_{\mathrm{V}} / \mathrm{F}_{\mathrm{M}}$ entre 93 e 107 dias foi maior (dados não apresentados).

Os valores médios obtidos no presente trabalho são similares aos encontrados por Björkman \& Demmig (1987), que avaliaram a relação $\mathrm{F}_{\mathrm{V}} / \mathrm{F}_{\mathrm{M}}$, em diferentes espécies e ambientes, e encontraram um valor médio de 0,830 . Porém, 
estão acima dos relatados por Li et al. (2004), que estudaram a relação $F_{v} / F_{M}$ para 99 espécies nativas com habitat diferentes da região da Mongólia e encontraram valores entre 0,57 a 0,79 , com média 0,76 , em função do tipo de planta, mecanismo fisiológico e local de crescimento, relatando para plantas $\mathrm{C}_{3}$ um valor médio de 0,72 .

A redução da relação $\mathrm{F}_{\mathrm{V}} / \mathrm{F}_{\mathrm{M}}$ foi também observada em plantas de batata cultivar Chunzao, quando infectadas pelo vírus $\mathrm{Y}^{\mathrm{NTN}}$, mas somente após 60 dias da infecção, indicando ausência de danos aos centros de reação do fotossistema II (FS II), antes deste período (Zhou et al., 2004).

O coeficiente de extinção fotoquímico (qP) representa a proporção da energia dos fótons capturada pelos centros de reação do FS II abertos e dissipada via transporte de elétrons (Juneau et al., 2005), refletindo o grau de oxidação e redução de $\mathrm{Q}_{\mathrm{A}}$. É responsável pelo decréscimo da fluorescência devido à separação de cargas fotoquímicas no centro de reação do FS II (Schreiber et al., 1986).

Para qP não foi observada interação significativa entre os fatores, de forma que ambos genótipos comportaram-se de forma similar, com valores médios iguais $(0,967)$. Verificou-se um aumento em qP até os 79 dias após o plantio, quando atinge o seu maior valor $(0,980)$, voltando a cair nas próximas datas atingindo o valor de 0,960 , não diferindo estatisticamente dos resultados obtidos aos 51 e 65 dias (Tabela 1), período que corresponde à fase de maior crescimento dos tubérculos, como descrito por Abreu et al. (2001). Em plantas de batata da cultivar Chunzao, que foram submetidas à infecção viral (PVY) ou não (controle), foi verificado por Zhou et al. (2004) um coeficiente de extinção fotoquímico $(\mathrm{qP})$ inferior a 0,600 para as plantas-controle e por volta de 0,200 para as plantas-PVY, aos 60 dias após a infecção. Estes valores encontram-se inferiores em relação a este trabalho, em decorrência da metodologia utilizada para obtenção dos mesmos. Este fato não invalida nenhuma das pesquisas, visto que Rohácek (2002) enfatiza que existem muitas formas para cálculo dos parâmetros de fluorescência, salientan-

Tabela 1. Variáveis de fluorescência das clorofilas medidos em plantas de batata, cultivar Baronesa e seu genótipo transformado, cultivadas em casa de vegetação (Variables of chlorophyll measured in either potato plants, cv. Baronesa and in its transformed genotype, cultivated under greenhouse conditions). Pelotas, UFPel, 2006.

\begin{tabular}{|c|c|c|c|c|c|c|}
\hline \multirow{2}{*}{ Variáveis } & \multirow{2}{*}{ genótipo } & \multicolumn{5}{|c|}{ Dias após o plantio } \\
\hline & & 51 & 65 & 79 & 93 & 107 \\
\hline \multirow{3}{*}{$\begin{array}{l}\text { Eficiência } \\
\text { fotoquímica } \\
\text { máxima }\left(F_{\checkmark} / F_{M}\right)\end{array}$} & Baronesa & 0,830 & 0,833 & 0,838 & 0,806 & 0,774 \\
\hline & $\begin{array}{l}\text { Baronesa } \\
\text { transformada }\end{array}$ & 0,844 & 0,837 & 0,842 & 0,823 & 0,828 \\
\hline & media & $0,837 \mathrm{~A}^{*}$ & $0,835 \mathrm{~A}$ & $0,840 \mathrm{~A}$ & $0,814 \mathrm{~A}$ & $0,801 \mathrm{~B}$ \\
\hline \multirow{3}{*}{$\begin{array}{l}\text { Coeficiente de } \\
\text { extinção } \\
\text { fotoquímico (qP) }\end{array}$} & Baronesa & 0,969 & 0,974 & 0,979 & 0,958 & 0,954 \\
\hline & $\begin{array}{l}\text { Baronesa } \\
\text { transformada }\end{array}$ & 0,958 & 0,965 & 0,981 & 0,961 & 0,967 \\
\hline & média & $0,963 \mathrm{AB}$ & $0,969 \mathrm{AB}$ & $0,980 \mathrm{~A}$ & $0,960 \mathrm{~B}$ & $0,961 \mathrm{~B}$ \\
\hline \multirow{3}{*}{$\begin{array}{l}\text { Coeficiente de } \\
\text { extinção não- } \\
\text { fotoquímico } \\
\text { (qN) }\end{array}$} & Baronesa & 0,167 & 0,140 & 0,147 & 0,136 & 0,183 \\
\hline & $\begin{array}{l}\text { Baronesa } \\
\text { transformada }\end{array}$ & 0,192 & 0,166 & 0,135 & 0,099 & 0,182 \\
\hline & média & $0,179 \mathrm{~A}$ & $0,153 \mathrm{AB}$ & $0,141 \mathrm{AB}$ & $0,117 \mathrm{~B}$ & $0,182 \mathrm{~A}$ \\
\hline \multirow{3}{*}{$\begin{array}{l}\text { Eficiência } \\
\text { fotoquímica } \\
\text { atual }\left(F_{V} / F_{M}{ }^{\prime}\right)\end{array}$} & Baronesa & 0,796 & 0,792 & 0,790 & 0,769 & 0,697 \\
\hline & $\begin{array}{l}\text { Baronesa } \\
\text { transformada }\end{array}$ & 0,805 & 0,791 & 0,794 & 0,790 & 0,771 \\
\hline & média & $0,800 \mathrm{~A}$ & $0,792 \mathrm{~A}$ & $0,792 \mathrm{~A}$ & $0,778 \mathrm{AB}$ & $0,734 \mathrm{~B}$ \\
\hline
\end{tabular}

*Médias seguidas pela mesma letra, maiúsculas nas linhas não apresentaram diferença significativa ao nível de 5\% de probabilidade pelo teste de Tukey, para cada parâmetro.

do que o importante é a interpretação dos mesmos.

De acordo com Juneau et al. (2005), o coeficiente de extinção nãofotoquímico (qN) representa a queda na fluorescência devido a processos nãofotoquímicos, sendo que corresponde a um aumento na perda de energia absorvida via dissipação térmica, ou seja, associado a todos os processos de des-excitação não-radiativos (Juneau et al., 2005). Para este parâmetro, não houve diferença significativa entre os genótipos $(0,155$ e 0,156 , respectivamente, para plantas da cultivar Baronesa e de seu genótipo transformado). Somente o fator época de análise apresentou efeito significativo, havendo decréscimo em qN a partir de 65 DAP e chegando ao seu menor valor aos 93 DAP (Tabela 1). Os menores valores de $\mathrm{qN}$ observados entre 65 e 93 DAP podem estar associados a uma maior eficiência no aproveitamento da energia luminosa pela utilização mais eficiente na formação de poder redutor e ATP na fase fotoquímica da fotossíntese.

Valores mais altos de $\mathrm{qN}$ foram encontrados por Zhou et al. (2004) trabalhando com a cultivar Chunzao, sendo relatado que os valores aumentaram durante o crescimento das plantas, che- gando próximo de 0,890 para as plantas infectadas pelo PVY e 0,850 para as plantas-controle, aos 60 dias após a infecção. Os mesmos autores atribuem um aumento em qN efetivamente à infecção pelo $\mathrm{PVY}$, associado à queda de $\mathrm{qP}$ devido a uma redução no consumo de ATP e poder redutor no ciclo de Calvin; visto que a relação $F_{v} / F_{M}$ não foi alterada, indicando que a infecção por vírus não causa alteração na eficiência fotoquímica máxima.

Outro parâmetro da cinética de fluorescência é a produção quântica fotoquímica efetiva do FS II $\left(\Phi_{2}\right.$ ou F ${ }_{\mathrm{v}}$ ') $\mathrm{F}_{\mathrm{M}}{ }^{\prime}$ ), obtida quando as folhas estão sob luminosidade, ou seja, realizando o processo fotossintético. Este parâmetro é extremamente útil porque representa a eficiência quântica efetiva das folhas, diferentemente da relação $\mathrm{F}_{\mathrm{v}} / \mathrm{F}_{\mathrm{M}}$ que indica a eficiência máxima em estado adaptado ao escuro, sendo este último maior do que o primeiro.

Não houve diferença entre os genótipos na eficiência fotoquímica atual $\left(\mathrm{F}_{\mathrm{V}}{ }^{\prime} / \mathrm{F}_{\mathrm{M}}{ }^{\prime}\right)$. Para as plantas do genótipo transformado o valor médio foi de 0,790 , e para o não transformado foi de 0,768 . Considerando o fator época de análise (Tabela 1), constatou-se uma queda a partir de 93 dias, o que pode estar asso- 
Tabela 2. Taxa de fotossíntese líquida $\left(\mu \mathrm{mol} \mathrm{CO}_{2} \mathrm{~m}^{-2} \mathrm{~s}^{-1}\right)$ e taxa de liberação de oxigênio $\left(\mu \mathrm{mol} \mathrm{O} \mathrm{m}^{-2} \mathrm{~s}^{-1}\right)$ medida em plantas de batata, cultivar Baronesa e seu genótipo transformado, cultivadas em casa de vegetação (Net photosinthesis rate $\left(\mu \mathrm{mol} \mathrm{CO} \mathrm{Cm}^{-2} \mathrm{~s}^{-1}\right)$ and oxygen evolution rate $\left(\mu \mathrm{mol} \mathrm{O} \mathrm{m}^{-2} \mathrm{~s}^{-1}\right)$ measured in potato plants, $\mathrm{cv}$. Baronesa and in its transformed genotype, cultivated in greenhouse). Pelotas, UFPel, 2006.

\begin{tabular}{|c|c|c|c|c|c|c|}
\hline \multirow{3}{*}{ Genótipos } & \multicolumn{6}{|c|}{ Taxa de fotossíntese líquida $\left(\mu \mathrm{mol} \mathrm{CO}_{2} \mathrm{~m}^{-2} \mathrm{~s}^{-1}\right)$} \\
\hline & \multicolumn{6}{|c|}{ Dias após o plantio } \\
\hline & 50 & 65 & 79 & 98 & 107 & Média \\
\hline Baronesa & 9,83 & 10,95 & 13,03 & 9,78 & 6,56 & 9,90 \\
\hline $\begin{array}{l}\text { Baronesa } \\
\text { transformada }\end{array}$ & 9,23 & 12,32 & 14,55 & 13,21 & 5,65 & 11,32 \\
\hline \multirow[t]{2}{*}{ Média } & $9,53 \mathrm{~B}^{*}$ & $11,63 \mathrm{AB}$ & $13,79 \mathrm{~A}$ & $11,48 \mathrm{AB}$ & $6,10 \mathrm{C}$ & \\
\hline & \multicolumn{6}{|c|}{ Taxa de liberação de oxigênio $\left(\mu \mathrm{mol} \mathrm{O}_{2} \mathrm{~m}^{-2} \mathrm{~s}^{-1}\right)$} \\
\hline \multirow[t]{2}{*}{ Genótipos } & \multicolumn{6}{|c|}{ Dias após o plantio } \\
\hline & 54 & 68 & 83 & 98 & 110 & Média \\
\hline Baronesa & $23,97 \mathrm{~A} \mathrm{a}^{*}$ & $18,59 \mathrm{~B} \mathrm{a}$ & $16,91 \mathrm{BC} \mathrm{b}$ & $10,57 \mathrm{Da}$ & $13,12 \mathrm{CD}$ a & $16,63 \mathrm{~b}$ \\
\hline $\begin{array}{l}\text { Baronesa } \\
\text { transformada }\end{array}$ & $30,12 \mathrm{~A} a$ & $20,60 \mathrm{BC}$ a & $23,27 \mathrm{~B}$ a & $11,49 \mathrm{D} a$ & $15,50 \mathrm{CD}$ a & $20,20 a$ \\
\hline Média & $27,04 \mathrm{~A}$ & $19,60 \mathrm{~B}$ & $20,09 \mathrm{~B}$ & $11,03 \mathrm{D}$ & $14,31 \mathrm{C}$ & \\
\hline
\end{tabular}

*Médias seguidas pela mesma letra, maiúsculas nas linhas não apresentaram diferença significativa ao nível de 5\% de probabilidade pelo teste de Tukey.

ciado com a queda nos teores de clorofilas. Esta mesma tendência à diminuição ao longo do tempo foi constatada por Zhou et al. (2004) que observaram uma eficiência fotoquímica atual para suas plantas de batata da cultivar Chunzao em torno de 0,600 aos 60 dias.

Deve-se destacar que os parâmetros de fluorescência analisados comparativamente entre os genótipos transformados e os não-transformados de batata cultivar Baronesa, apenas a relação $\mathrm{F}_{\mathrm{v}} /$ $\mathrm{F}_{\mathrm{M}}$ apresentou diferença significativa, podendo-se supor que a introdução do gene $\mathrm{CP}$, que codifica para a proteína do capsídeo do vírus Y, possa, de forma incerta, ter proporcionado um benefício na eficiência fotoquímica máxima.

Com relação à taxa fotossintética líquida, não houve interação entre os fatores isolados (Tabela 2), havendo apenas diferença para o fator época de análise. Foi observado aumento na taxa fotossintética líquida com o desenvolvimento das plantas, sendo os maiores valores obtidos entre 65 e 93 DAP, o que corresponde ao período de aumento dos drenos (Abreu et al., 2001). Os valores médios para esse parâmetro foi de 9,90 $\mu \mathrm{mol} \mathrm{CO}_{2} \mathrm{~m}^{-2} \mathrm{~s}^{-1}$ para as plantas do genótipo não-transformado e $11,32 \mu \mathrm{mol}$ $\mathrm{CO}_{2} \mathrm{~m}^{-2} \mathrm{~s}^{-1}$ para as plantas do genótipo transformado. Observou-se também, uma ligeira superioridade na taxa de fotossíntese líquida nas plantas transformadas, principalmente no período de formação e crescimento dos tubérculos. Os dados obtidos nesse trabalho encontram-se próximos, porém inferiores, aos relatados por Basu et al. (1999), que trabalharam com batata cultivar Kufri Sindhuri sob condição de remoção ou não de tubérculos, e associados ou não à supressão da irrigação. Estes autores realizaram determinações sob densidade de fluxo de fótons de $1500 \mu \mathrm{mol} \mathrm{m}{ }^{-2}$ $\mathrm{s}^{-1}$, diferentemente do presente trabalho, em que as leituras foram realizadas com radiação em condições ambientais.

Zhou et al. (2004) examinaram respostas fotossintéticas de batata, cultivar Chunzao, durante infecção (PVYNTN) e constataram que esta provocou redução significativa na taxa de fotossíntese das plantas. Aos 60 dias após a infecção, as plantas-controle apresentaram valores próximos a $13 \mu \mathrm{mol} \mathrm{CO} \mathrm{Cm}^{-2} \mathrm{~s}^{-1}$, enquanto que as plantas infectadas apresentaram valores próximos a $9 \mu \mathrm{mol} \mathrm{CO}_{2} \mathrm{~m}^{-2} \mathrm{~s}^{-1}$.

Para a taxa de liberação de oxigênio, houve interação entre os fatores genótipo e época de análise (Tabela 2). Verificou-se uma queda na taxa de fotossíntese potencial tanto nas plantas não-transformadas quanto no genótipo transformado durante o desenvolvimento das plantas, sendo esta mais acentuada nas plantas não-transformadas. Os menores valores foram encontrados aos 98 DAP para ambos os genótipos e as maiores taxas de fotossíntese potencial determinadas aos 54 DAP $(27,04 \mu \mathrm{mol}$ $\left.\mathrm{O}_{2} \mathrm{~m}^{-2} \mathrm{~s}^{-1}\right)$. Neste período, segundo Kooman \& Rabbinge (1996), os tubérculos já se encontram formados, mas em fase de alta demanda de carboidratos.

Não é conhecido como os tubérculos regulam a taxa de fotossíntese líquida e o pool de carboidratos nas folhas. Há algumas evidências que indicam que há forte influência dos drenos (tubérculos) sobre a fotossíntese e a partição de assimilados. Um aumento na taxa de fotossíntese líquida acoplada com a intensificação da translocação de fotoassimilados (Dwelle et al., 1981) tem sido associado com um correspondente aumento na demanda dos drenos ou quando os tubérculos estão crescendo rapidamente. De forma alternativa, a remoção de tubérculos que estão crescendo rapidamente leva a uma marcante depressão na taxa de fotossíntese líquida, devido a um desbalanço entre a fonte e os drenos (Nosberger \& Humphries, 1965).

As plantas de batata, cultivar Baronesa, transformadas com genes de resistência ao vírus $\mathrm{Y}$ apresentaram maior eficiência fotoquímica máxima e maior taxa de liberação de oxigênio (fotossíntese potencial) do que plantas da mesma cultivar não modificadas geneticamente, embora mantenha os demais parâmetros de fluorescência das clorofilas e a taxa de fotossíntese líquida iguais.

\section{AGRADECIMENTOS}

À FAPERGS e FINEP pelo auxilio financeiro; ao MCT/CNPq e CAPES pela concessão das bolsas de produtividade e pós-graduação.

\section{REFERÊNCIAS}

ABREU CM; BACARIN MA; PEREIRA AS; LIMA MGS. 2001. Composição bioquímica em tubérculos de diferentes genótipos de batata cultivados em casa de vegetação. Revista Ceres 48: 593-599.

ALLAHVERDIEV SR; MAVITUNA M; GANIEVA R; NAFISI S. 1998. Effects of salt stress and synthetic hormone polystimuline $\mathrm{k}$ on photosynthetic activity of Trianea bogotensis Karst. Journal of Botany 22: 1923. 
BACARIN MA; MOSQUIN PR. 2002. Cinética de emissão de fluorescência das clorofilas de dois genótipos de feijoeiro. Ciência Agrotécnica 26: 705-710.

BASU PS; SHARMA A; GARG ID; SUKUMARAN, NP. 1999. Tuber sink modifies photosynthetic response in potato under water stress. Environmental and Experimental Botany 42: 25-39.

BJÖRKMAN O; DEMMIG B. 1987. Photon yield of $\mathrm{O}_{2}$ evolution and chlorophyll fluorescence characteristics at $77 \mathrm{~K}$ among vascular plants of diverse origins. Planta 170: 489-504.

BORÉM A. 2001. Escape gênico e transgênicos. Viçosa, Editora UFV. 204p.

BRASILEIRO AC; DUSI DMA. 1999. Transformação genética de plantas. In: TORRES AC; CALDAS LS; BUSO JA. (eds.). Cultura de Tecidos e transformação genética de plantas. Brasília: SPI/EMBRAPA - CNPH. p.679-736.

CAMPOS MA. 1995. Sistema de transformação de batata (Solanum tuberosum L.) cultivar Baronesa mediado por Agrobacterium tumefaciens. Pelotas: FAEM/UFPel. 93p. (Tese mestrado).

COSTA DM; CASTRO LAS; PETERS JA. 1989. Batata: a busca de maior produtividade. Horti Sul 1: 40-42.

DWELLE RB; KLEINKOPF GE; PAVEK JJ. 1981. Stomatal conductance and gross photosynthesis of potato (Solanum tuberosum L.) as influenced by irradiance, temperature and growth stage. Potato Research 24: 49-59.

FERREIRA, AT; INOUE-NAGATA, A; ROMANO, E; ÁVILA, AC.; PETERS, JA; TORRES, AC; MONTE, DC. 1999. Avaliação de plantas de batata (cvs. Baronesa e macaca) transformadas com o gene viral visando obtenção de plantas resistentes ao vírus do enrolamento das folhas (PLRV). Fitopatologia Brasileira, v.24 (suplemento), p.353-354. Resumos.
FOXE MJ. 1992. Breeding for viral resistance: conventional methods. Netherlands Journal of Plant Pathology 98: 13-20.

GRANT SR. 1999. Dissecting the mechanisms of posttranscriptional gene silencing: Divide and Conquer. Cell 96: 303-306.

JUNEAU P; GREEN BR; HARRISON PJ. 2005. Simulation of Pulse-Amplitude-Modulated (PAM) fluorescence: Limitations of some PAM-parameters in studying environmental stress effects. Photosynthetica 43: 75-83.

KOOMAN PL; RABBINGE R. 1996. An analysis of the relation between dry matter allocation to the tuber and earliness of potato crop. Annals of Botany 77: 235-242.

KRAUSE GH; WEIS E. 1991. Chlorophyll fluorescence and photosynthesis: the basics. Annual Review of Plant Physiology and Plant Molecular Biology 42: 313-349.

LI YG; LI LH; JIANG GM. 2004. Traits of chlorophyll fluorescence in 99 plants species from the sparse-elm grassland in Hunshandak Sandland. Photosynthetica 42: 243-249.

MAXWELL K; JOHNSON GN. 2000. Chlorophyll fluorescence - a practical guide. Journal of Experimental Botany 51: 659-668.

NOSBERGER J; HUMPHRIES EC. 1965. The influence of removing tubers on dry matter production and net assimilation rate of potato tubers. Annals of Botany 29: 579-588.

PEREIRA AS; SOUZA ZS; CHOER E. 2003. Principais cultivares. In: PEREIRA AS; DANIELS J. (eds.). O cultivo da Batata na Região Sul do Brasil. Brasília: Embrapa Informação Tecnológica. 567p.

ROHÁCEK K. 2002. Chlorophyll fluorescence parameters: the definitions, photosynthetic meaning, and mutual relationships. Photosynthetica 40: 3-29.

ROHÁCEK K; BARTÁK M. 1999. Technique of the modulated chlorophyll fluorescence: basics concepts, useful parameters, and some applications. Photosynthetica 37: 339-363.
SCHREIBER U; SCHLIWA U; BILGER W. 1986. Continuous recording of photochemical an non-photochemical chlorophyll fluorescence quenching with a new type of modulation fluorometer. Photosynthesis Research 10: 51-61.

SLATER A; SCOTT N; FOWLER M. 2003. Plant Biotechnology: the genetic manipulation of plants. Oxford: Oxford University Press. 347p.

TRUSKINOV EV; ROGOZINA EV. 1997. Elimination of viruses from a potato clone collection by tissue culture. Russian Journal of Plant Physiology 44: 374-380.

VAYDA ME.; BELKNAP WR. 1992. The emergence of transgenic potatoes as commercial products and tools for basic science. Transgenic Research 1: 149-163.

ZHOU YH; PENG YH; LEI JL; ZOU LY; ZHENG JH; YU JQ. 2004. Effects of potato virus $\mathrm{Y}^{\mathrm{NTN}}$ infection on gas exchange and photosystem 2 function in leaves of Solanum tuberosum L. Photosynthetica 42: 417-423. 